\title{
Methods of industrial and educational designing of furniture in the training of secondary school students and vocational education in design activities
}

\author{
Yu. V. Sokotov \\ Ternopil National Pedagogical University named after Volodymyr Hnatyuk, Ternopil, Ukraine \\ Corresponding author. E-mail: juriy2104@gmail.com
}

Paper received 01.02.19; Accepted for publication 06.02.19.

\begin{abstract}
https://doi.org/10.31174/SEND-PP2019-187VII76-14
\end{abstract}
Abstract. The essence of designing methods is described in the article. The methods of industrial design of furniture are selected for
the purpose of activating the design thinking and regulation of creative search. The methods of educational design at the organiza-
tional-preparatory and design stages of project and technological activity of high school students and vocational education have been
selected. It has been determined that the fundamental category that determines the design process is the purpose of the project, and
the design activity at the enterprises is preceded by a training project, the motives of which are social and personal needs.

Keywords: methods of search and formation of new ideas, methods of teaching design, design technology of training, design activity.

Introduction. The development of the mass design culture, the world orientation of furniture designing is accompanied at the present stage by the creative activity of people in the organization of the subject-spatial environment, the creation of new values and norms of material and spiritual life. Making furniture is a complex creative and organizational process. It involves the analysis and ideologically oriented understanding of the design object, its scientific and artistic modeling, as well as adequate methods for creating project ideas and concepts [6].

The subject of the work of designers is the design itself, its essence and form. The fundamental category that defines the design process is the purpose of the project. Approaches to the design object, the point of view on it and the specifics of the design activity determine the main categories of project designer activities [5]. These include the "design image", "the functions of the subject", "the morphology of the subject," "the technological form of the object," "aesthetic value" with its corresponding definition and role in designing [7, pp. 19-20].

According to O. M. Kobernyk and H. V. Tereshchuk: "under design in the general sense it is necessary to understand the scientifically substantiated construction of the parameters system of the future object or qualitatively new state of the existing prototype project, the prototype of the intended or possible object, state or process in unity with the ways of its achievement "[3, p. 21].

Recently, the idea of the nature of the design, its scope of use has changed significantly. Until lately, designing was associated mainly with engineering activities in the fields of mechanical engineering, instrumentation, architecture and was understood as the preparatory stage of production activity. Currently, design is considered as a special type of activity, different from the actual scientific and production activities, and the scope of its application covers all parts of the social organism, including the education system [3, p. 22]. This assertion is confirmed by the transition of the education system from the subjectoriented to the problem-oriented study, that is, through the creative projects fulfilled by the students of both secondary and vocational education.

A brief overview of publications on the topic. The theoretical foundations and methodology of furniture design, general designing and furniture typology, materials on the historical development of the forms of individual types of furniture, the social, functional, bionic, informational, ergonomic, design, technological, economic and aesthetic aspects of furniture design are highlighted in the works of A.A. Bartashevych, V. D. Bohush, J.K. Jones, S. P. Myhal, V. M. Tarnavskyi and others. The works of O. M. Kobernyk, V. K. Sydorenko, H. V. Tereshchuk, S. M. Yashchuk, and others are dedicated to the problem of teaching design work as a project technology for teaching secondary school students and students of vocational education.

The goal is to substantiate expediency of application of methods of industrial and educational designing of furniture in preparation of students of high school and vocational education for designing activity.

Materials and methods. The basis of the organization and presentation of the material is the competence approach, focused on the formation of theoretical and practical readiness for design activities. Subject of research: the definition of methods of industrial and educational design of furniture, which provides training for secondary school students and vocational education in design activities. As the methods of theoretical research, comparisons, comparative analysis, generalizations of scientific literature, inductive and deductive methods have been used.

Results and discussion. Designing as a creative, innovative activity is always aimed at the independent activity of students - an individual, pair, group, which is performed within a certain period of time to create an objectively and subjectively new product $[3$, p. 22]. The value of designing is that this activity teaches children to independent, practical, planned and systematic work, educates the desire to create a new or existing, but improved product, forms an idea about the prospects of its application, develops the moral and labor qualities.

Activity that involves the justification and design of a construction, the technology of manufacturing and implementation of the design object and is aimed at forming a certain system of creatively-intellectual and subjecttransforming knowledge and skills in education is called the design-technological. The content of the projecttechnological activity consists of the following stages, which are interrelated and effectively reveal the sequence of development and implementation of the project: organizational, preparatory, design, technological, and final [3].

We will consider only the first two stages, which, in 
our opinion, include the basic laws of industrial design in a modified or simplified form for the educational process, in particular, the design and technological activities of students. So, at the first stage of the project activity students face the problem: to choose the right design element correctly. At this stage students must choose and challenge themselves, realize the value of the future product for themselves, and for society as a whole, that is, to determine the feasibility of a project. Students form and offer various ideas, and later variants of design, define and discuss the optimal variant of the proposed design, the most successful parameters of its future design from the point of view of the conditions of use, own experience and experience of others. Thus, they generate ideas that are the most important element in the design and technological activities. The student learns to analyze, compare, generalize, make corrections, plans his next activity. Besides, he/she summarizes the study material, including it thereby in the general system of their knowledge and skills. The final element of this stage will be generalization and design definition.

The first stage of the project-technological activity consists of the following stages: problem search; awareness of the problem sphere; development of ideas and options; formation of basic parameters; selection of the optimal option and justification of the project; analysis of future activity; forecasting future results. The means of activity are personal experience of students, experience of teachers, parents, and also mass media -- magazines, books, the Internet, etc. The results of the students' activity at this stage are the acquisition of new knowledge, skills and a definite optimal design variant.

At the organizational-preparatory stage, in addition to verbal methods (narratives, explanations), methods are used to demonstrate samples of previously executed projects, information support, brainstorming, etc.

For comparison, in the industrial design of furniture, in order to enhance design thinking and regulation of creative search methods used are given in Table 1 [2].

Table 1. Methods of searching and developing new ideas

\begin{tabular}{|c|c|}
\hline Method & Goal \\
\hline Heuristic analogy & $\begin{array}{l}\text { Search and use of similarity of objects, elimination of contradictions contained in the } \\
\text { problem design situation }\end{array}$ \\
\hline Heuristic inversion & Search for solutions to problems in the directions which are opposite to the traditional ones \\
\hline Heuristic complex & $\begin{array}{l}\text { Heuristic unification of ideas, concepts, objects, their elements, processes, functions, and } \\
\text { operations }\end{array}$ \\
\hline $\begin{array}{l}\text { Heuristic disintegration and } \\
\text { reduction }\end{array}$ & $\begin{array}{l}\text { Using the ability of analytical thinking to divide subjects and phenomena into components } \\
\text { with the allocation of causal relationships }\end{array}$ \\
\hline \begin{tabular}{|l|} 
Selection of visual \\
inconsistencies
\end{tabular} & Setting directions for finding ways to refine a design solution \\
\hline Check Questions & Reducing the psychological inertia of thinking and streamlining the search for solutions \\
\hline Brainstorming & Search for creative solutions when considering and generating a large number of alternatives \\
\hline Synectics & $\begin{array}{l}\text { Orientation of the spontaneous activity of the brain and the nervous system to study the } \\
\text { design problem }\end{array}$ \\
\hline $\begin{array}{l}\text { Design in imaginary } \\
\text { conditions }\end{array}$ & $\begin{array}{l}\text { Assistance in the development of creative imagination, search of non-trivial ways to solve a } \\
\text { project problem }\end{array}$ \\
\hline "Black Box" & $\begin{array}{l}\text { Definition by the side way of the reaction of the input quantities to change the output, and } \\
\text { vice versa }\end{array}$ \\
\hline Morphological maps & $\begin{array}{l}\text { Definition of the functions of the subject, as well as a wide range of alternative means of } \\
\text { implementing each function, establishing structural relationships and relationships between } \\
\text { elements, objects, and ideas }\end{array}$ \\
\hline Overcoming deadlocks & $\begin{array}{l}\text { Finding new directions for finding a solution to a project task, when an explicit area did not } \\
\text { provide an acceptable solution }\end{array}$ \\
\hline Matrix of interactions & Ensuring a systematic search for relationships between elements within a given problem \\
\hline Network of interactions & Reflection of the scheme of interconnections between elements within the design problem \\
\hline \begin{tabular}{|l|} 
Analysis of interrelated \\
decision areas
\end{tabular} & $\begin{array}{l}\text { Identification and evaluation of all compatible combinations of partial solutions to the } \\
\text { design problem }\end{array}$ \\
\hline Transformation of the system & Finding ways to transform the system to eliminate its inherent weaknesses \\
\hline \begin{tabular}{|l|l|} 
Designing innovations by \\
shifting boundaries
\end{tabular} & $\begin{array}{l}\text { The shift of the boundaries of the unsolved design problem so that the knowledge of related } \\
\text { branches could be used to solve such a problem. }\end{array}$ \\
\hline Designing new features & Creating a radically new design that can lead to new patterns of behavior and demand \\
\hline Goal tree & $\begin{array}{l}\text { Coverage of all necessary areas of the project activity, planning of research related to the } \\
\text { solution of the problem }\end{array}$ \\
\hline Questionnaire & Determination of the trends of the object being developed by analyzing personal data \\
\hline $\begin{array}{l}\text { Classification of design } \\
\text { information }\end{array}$ & Division of the project problem into parts that can be solved \\
\hline
\end{tabular}

Creation of various forms of furniture from a limited number of elements is carried out according to certain rules of interfaces and connections of constituent parts. An important means to improve many types and kinds of products of modern mass production is the use of a combinatorial method of forming, which allows to obtain a large number of composite solutions from multiple repetitive standard unified elements [7, p. 22].

The main method of the design process is to overcome the contradictions between aesthetic and economic, aesthetic and standard, individual and mass, personal and impersonal, unique and typical [7, p. 22].

In the process of educational design and technological activities, one can distinguish the following methods of 
design and development of students: the method of fantasy, the method of samples (algorithmic analysis), the method of focal objects, the method of creating the image of the ideal object, the basis of the theory of algorithm solving inventive problems (ASIP) [3, p. 47].

The method of fantasy means a way of joint activity of students and teachers when it comes to presenting the non-existing image of an object (product) that functions and solves the problem, that is, the solution to a problem, even if some elements of the design (or the whole structure) of this object is unknown. The main condition of the method of fantasy is the absence of any restrictions, rules, postulates, logical and critical thinking. The starting point in fantasy must be a certain problem or inventive task that needs to be solved.

Sample method (algorithmic analysis) is a kind of "training" that teaches students the ability to switch from the process of fantasy to the more critical (in terms of functional requirements) technological thinking. It is a simplified version of the "algorithm for solving inventive problems" method. The essence of this method is the consistent implementation of actions to identify, clarify and eliminate technical contradictions: the formulation of an ideal solution (or the adoption of the creation of an ideal object); transition from technical contradiction to physical; elimination of physical contradiction; application of operators that reflect information in the most effective ways to overcome the contradiction. To implement the algorithmic method in teaching the pupils to project activity, this method can be simplified to the level of the sample method.

The method of focal objects was invented by American scientist Ch. Whiteing. An object that is refined with this method is called focal, since it is placed in the focus of attention (focus). The essence of the method is based on the transfer of signs of randomly selected objects to focal, resulting in unusual combinations that allow you to overcome psychological inertia. This method is used primarily when it is necessary to upgrade, modernize any technical object.

The essence of the method of creating an image of the ideal object can be represented in the form of the following steps: clear formulation of the problem (problem statement); definition of properties or parameters which the object should have (to solve the problem); shaped object modeling with the appropriate set of qualities that will enable to solve the problem; schematic or artistic transfer of a certain image to paper. Comparison of the ideal solution with the actual technical object allows us to identify a technical contradiction, its cause is a physical contradiction. A certain type of contradiction is eliminated by a small number of techniques. After overcoming the contradiction, they make a technical decision and begin to develop the idea. The process is completed by calculation decision, which includes the substantiation of the main characteristics of the invention. These stages are the transition from the solution to the search task to the design development of the invention.

The ASIP theory implies the formulation of the original problem in general terms. Finding an idea in any inventive task begins by constructing a model of a task, which is filled only with those elements, the conflict between which creates a technical contradiction. This method of search was developed by G. Altshuller [1], which fundamentally differs from all other methods by its rationality.

Success and efficiency of designing is provided by the correct and organizationally consistent planned work of the teacher and student, based on the logical sequence of compliance with the design stages.

At the second, at the design stage, it is interesting to us that the students make a sketch of their most perfect and best design, which meets the modern requirements and design, and selects materials. This is nothing other than the design process -- the compilation of the description necessary for the creation in the given conditions of an existing object, or an algorithm for its operation with possible optimization of the given characteristics of the object or algorithm for its operation.

On an industrial scale, the stages of development of design documentation for carpentry and furniture products are: a technical task, a technical proposal, a sketch project, working documentation [7, p. 19].

The specification establishes the main purpose, technical characteristics, indicators of quality and technical and economic requirements for the product being developed, the implementation of the necessary stages of development of design documentation and its composition, as well as special requirements for the product. The specification is developed by the customer and is in agreement with the developer [7, p. 19].

Technical proposal is a document containing technical and feasibility studies on the feasibility of developing documentation of a product on the basis of an analysis of the customer's technical specification and various options for possible product solutions, a comparative assessment of solutions, taking into account the design and operational features of the product being developed, as well as patent materials.

Draft project is a set of design documents, which must contain basic constructive solutions that give general ideas about the device and the principle of how products work, as well as data defining the purpose, the main parameters and overall dimensions of the product being developed. At the stage of designing a sketch project, layout design may be provided.

The working documentation of design documents is developed for the production, testing and review of prototypes, the production of guiding series and the main (control) series of stable serial or mass production [7, p. 19].

The peculiarity of designing furniture solutions is a thorough analysis of each design and creative decision on the subject of conformity to the functional and technological process, its technical and economic indicators, the integral artistic model of the subject-spatial environment and the image of the person for which they are designed.

Getting fast and quality results in modern production conditions can be achieved using information and communication technologies, which are increasingly implemented both in production and in educational process for the design of premises and cabinet furniture every year with the help of various software environments that allow to quickly develop a design of good quality, get visual illustrations, detailed assembly and working drawings of parts. 
In the process of project activity, it is important for students to realize: at all stages there should be not reproductive, that is strictly consistent observance of stages and elements of stages, but the students' mastering of the algorithm of the organization, the formation of elements of creativity in them, development of the ability to generate ideas, their analysis, independent decision making, formulation of their own opinion, position, interaction and dialogue in the process of solving common problems, development and production of projects. The formation of designer furniture solutions is a creative task of a modern designer. Many years of experience in the development of mankind confirms that none of a designer's ways to solve a particular creative problem can be considered to be stable and/or intact, because there is no such thing in the world that could not be improved.

Understanding the design of the furniture, the completeness and integrity of its perception depends not only on the object and professional skill of the designer, but also on the consumer: the level of his/her life experience, artistic taste, world perception. The condition of fullfledged aesthetic mastering of objects is the general nature of creativity [4], the presence and the possibility of development in all subjects of the design process and the process of consumption of qualities: aesthetic perception; aesthetic consciousness; aesthetic measure. From the fact how the artistic image that arose in the minds of the consumer is adequate to the designer's ideas depends the result of mastery and creativity. Therefore, at the stages of external and internal designing during the search for an artistic image, it is very important for the designer to understand and express with the help of architectural and artistic means the meaningfulness, visual integrity and certainty of the created products. The expressiveness and comfort of furniture, the creation of optimal conditions for human life ultimately depend on the skill of the designer and his/her creative installations [7, p. 23].

Conclusions. Thus, educational design assigns the following tasks: to prepare students for industrial and technical, design and development activities at enterprises, factories, the creation and introduction of new design solutions for the design of products, in particular, furniture.
A guarantee of activity aimed at creating new forms of furniture, a holistic harmonious subject-technical environment of human life is to create an effective organizational structure for work on the formation and selection of new ideas, conceptual design, marketing research, analysis of production and consumption opportunities, product development, its testing, production and consumption, making justified decisions at every stage of the life cycle. Consequently, these decisions, which are inseparable from a designer's ones, confirm the conclusion that the development of design may lead to the absorption of other varieties of design, or rather, dissolve in a single project method based on the general theory of designing [7, p. 19].

In order to teach designing, the motives of such activities are social and personal needs in the material and spiritual values. The housing environment is characterized by the cyclicality and rhythm of the processes occurring in it. Therefore, during designing it is necessary to take into account the socio-demographic characteristics of the family, its needs; changes in its composition; interconnections of all kinds of activities; influence of value orientations of man and various social groups; the influence of the design object on the person's psycho-physical condition, etc.

Ideally, students as future technologists, designers, designers should learn to see the problem area, taking into account their own needs or needs of the society and working on this problem apply creative methods and seek ways to solve the problems.

We can see the prospect of further inquiries in the examined area in the substantiation and development of furniture design technology by means of CAD systems as one of the stages of implementation of educational projects that will enable students, both secondary and vocational, to quickly and effectively master modern knowledge of the latest achievements, skills of independent practical activity for creative solution of complex production tasks, become professionally mobile, creative and constantly increase one's professional level of design activities.

\section{REFERENCES}

1. Altshuller G. S. Algorithm of the invention. K.: High school. 1979. $176 \mathrm{p}$.

2. Jones J.K. Design Methods: Translated from English. 2nd ed. M .: Mir, 1986. 326 p.

3. Innovative pedagogical technologies in labor education: Educational methodical manual (trial edition) / Edited by $\mathrm{O}$. M. Kobernyk, H. V. Tereshchuk. Ternopil-Uman, 2007. 208 p.

4. Meilakh V. S. The process of creativity and artistic perception. M., $1985.318 \mathrm{p}$.

5. Methodology of artistic design. 2nd improved edition. M .: VNIITE, 1983.

6. Mygal S.P. Fundamentals of Furniture Design: Educational Manual. Lviv, 1989. 168 pp.

7. Mygal S.P. Designing of furniture. Lviv: Svit, 1999. 216 p. 